\title{
AN ALTERNATIVE SOLUTION TO THE NARCOTICS PROBLEM
}

\author{
HubERT S. HowE*
}

Although the history of narcotic drug use is long, indeed, in this country, we naturally think of it in the light of conditions that have developed since the passage of the Harrison Act in I9r..$^{1}$ 'This act, as subsequently amended, together with the court decisions and administrative directives that have interpreted it, have created the environment of addiction as we know it today.

These Federal regulations embody a philosophy of approach to the problem of drug addiction. First, it reflects the view that it is possible to stop the spread of drug addiction by prohibition of the drug. Deprivation of the drug is to be accomplished by stopping supply. Secondly, it reflects a punitive approach in that stiff penalties are to act as a deterrent. Thirdly, by virtue of possession or of selling the drugs, the drug addict is regarded as a criminal. Among violators of the narcotic laws no distinction is drawn between addicts and non-addicts. Fourthly, it exercises rigid control over the physician in the practice of medicine. It makes the physician responsible for administration of the drug; but it sets down medical opinions on prognosis and dictates the kind of treatment in statutes. The Harrison Act itself did not attempt to deal with the problems of the addict; it attempted only to regulate the flow of narcotic drugs. The interpretations of the act, however, have altered what appears to have been the original intent of the measure in such a way that it is now difficult for physicians to render medical care to narcotic addicts except under carefully prescribed circumstances. ${ }^{2}$

Under these circumstances, few are familiar with the problem of addiction, and impressions are often second-hand. Not surprisingly, therefore, at least two important misconceptions have gained rather widespread currency and have, to a greater or lesser extent, conditioned popular attitudes toward addiction. The first of these misconceptions is that addicts under the influence of narcotic drugs are vicious and abnormal in their conduct-the stereotyped "drug fiend"-a notion probably derived from fanciful pulp stories, and seemingly fortified by observation of the bizarre effects of overindulgence in alcohol. It is common knowledge, of course, that the behavior of the alcoholic is abnormal when a sufficient concentration of alcohol is reached in his blood; his reactions are natural and normal only when he is without

* A.B. I908, A.M. I909, University of Denver; M.D. I912, Columbia University. Chairman, Subcommittee on Drug Addiction, New York Academy of Medicine; Chairman, Subcommittce on Treatment of the Committee on Narcotics Among Teen-Age Youth, Welfare and Health Council of New York City. Clinical Professor of Neurology, Columbia University, 1936-53. Author, Narcomcs AND Youth (r953), Treatalent of Withdrawal Symptoms of Persons Addicted to Narcotic Drugs (1954), and various works on neurology and psychiatry. Contributor to medical periodicals.

With deep regret, the editors of Law and Contemporary Problems record the death of Dr. Howe, shortly before the publication of this symposium. The editors are honored in the opportunity to present this paper, written by Dr. Howe in the closing months of his life-the product of his rich experience and his intimate interest in problems of narcotics addiction and its treatment.

${ }^{1}$ Act of Dec. I7, I9I4, c. I, 38 Stat. 785,26 U. S. C. $\$ \$ 4701-36$ (Supp. III, 1956).

${ }^{2}$ Subcommittee on Drug Addiction, New York Academy of Medicine, Report on Drug Addiction, 31 Buzc. N. Y. ACAD. MEd. 592, 596 (1955). 
it. Many, accordingly, assume that the same is the case with narcotic drugs; but nothing could be farther from the truth-in fact, the situation is just the reverse. When he has a sufficient concentration of narcotic drugs in his blood, then and only then is the addict normal and comfortable; when he is without them, he is in acute pain and will go to any necessary length to obtain them to relieve his suffering.

The other popular misconception is that the use of narcotic drugs necessarily warps the personality of the user and produces criminal tendencies. The demonstrable fact is, however, that it is not narcotic drugs themselves, but rather their exorbitant black-market cost that forces most addicts into criminal pursuits. It is significant, for example, that those addicts who can afford the high prices usually do not engage in crime and are, thus, unknown to the courts. This has been attested by Judge Jonah J. Goldstein, of the New York Court of General Sessions, who recently observed: "In the twenty-four years of my judicial service, I have never had a rich narcotic user brought before me, nor have $I$ heard of a rich narcotic user being brought into the court before any other judge." 3 Thus, while the addict must assume the responsibility for having foolishly, ignorantly, or accidentally contracted a devastating habit, the public must accept responsibility for having, through a punitive complex of law and regulations, classified him as a criminal and driven him into a life of crime.

Any philosophy of narcotic drug control that tends to foster misconceptions such as these quite obviously cannot come squarely to grips with the problem of addiction -and this has been amply demonstrated by our dismal forty-two years' experience under the Harrison Act. The plain fact of the matter is, of course, that addiction is a disease, both medical and social in etiology -as has been recognized in virtually all western countries-and we cannot successfully combat it until we acknowledge and treat it as such.

The medical and social aspects of addiction are quite extensively discussed elsewhere in this symposium, and the rationale and operative effectiveness of extant narcotic drug control legislation, both here and abroad, are searchingly analyzed. ${ }^{*}$ Accordingly, the writer will not expatiate on these matters, but rather will confine himself principally to a brief exposition of a solution that has acquired some following-that embodied in the recommendations of the New York Academy of Medicine of the myriad proposals that have been advanced for dealing with the narcotic drug problem, is, perhaps, the most fully rounded and carefully considered: ${ }^{5}$

The Academy proposes a six-point program to achieve these objectives. It should be emphasized that all measures are to be instituted, not just one.

x. There should be a change in attitude toward the addict. He is a sick person, not

${ }^{3}$ Hearings before the Subcommittee on Improvements in the Federal Criminal Code of the Senatd Judiciary Committee, 84th Cong., Ist Sess. pt. 5, at 1347 (1955).

'This does not, of course, necessarily constitute an endorsement by the writer of all of the views that appear in this symposium.

5 Subcommittee on Drug Addiction, supra note 2, at 603-06. 
a criminal. That he may commit criminal acts to maintain his drug supply is recognized; but it is unjust to consider him criminal simply because he uses narcotic drugs.

2. The Academy believes that the most effective way to eradicate drug addiction is to take the profit out of the illicit drug traffic. The causes of addiction are cited as: maladjustment, underprivilege, broken home, poverty. Such conditions may well be contributory factors, but they are not of themselves the prime cause. Rather, profit looms large as the principal factor.

The addict should be able to obtain his drugs at low cost under Federal control, in conjunction with efforts to have him undergo withdrawal. Under this plan, these addicts, as sick persons, would apply for medical care and supervision. Criminal acts would no longer be necessary in order to obtain a supply of drugs and there would be no incentive to create new addicts. Agents and black markets would disappear from lack of patronage. ...

3. An integral part of the program would be medical supervision of existing addicts, with vigorous efforts toward their rehabilitation. No particular philosophy of stamping out drug addiction ... has an exclusive proprietary of rehabilitation. Whatever the method it must include a plan and operation to rehabilitate the existing addict. This objective carries three parts: (I) persuasion of the addict to undergo treatment and rehabilitation; (2) appraisal of the methods of treatment and their success; (3) supervision of addicts who were resistant to undergoing treatment or refractory to treatment.

- ...

4. It is proposed that there be no relaxation in the efforts toward complete and permanent elimination of the supply of illegal narcotic drugs and that provisions for suppression ... be retained. ...

-...

It should be emphasized that the law should draw a distinction between the addict and non-addict in its provision. The convicted non-addict trafficker should feel its full forcc.

5. Adolescent addicts are reported to have said that they would not have taken drugs in the first place if they had known that they were going to become addicted. Such statements of youth are a strong argument for a good educational program for young people. The adult user, too, reports that he did not know the dangers of narcotic drugs when he began their use. If such reports are correct, it would appear that an educational program for adults as well as for adolescents is needed.

....

6. One of the great difficulties in planning for a medical approach in the care and supervision of addicts is the lack of accurate information on their number. So long as they are stamped as criminals that difficulty will exist. It is a merit of the medical approach that by adopting the proper attitude toward them, it should be possible to study the epidemiology of drug addiction and acquire information about the magnitude and pathogenesis of the disease.

By means of the records accumulated at the central agency, it would be possible to have at all times an accurate count of the known resistant addicts in the country....

Whenever mention is made, however, of medically supervised administration of narcotic drugs to addicts, it is likely to evoke the response that something similarclinics-was tried unsuccessfully many years ago. Much misinformation has been circulated concerning "the failure" of these institutions, and although no responsible 
authority seriously advocates revival of the clinics of I9r9-23, a recapitulation of their experience may be instructive.

After passage of the Harrison Act, doubts as to its constitutionality stayed the enforcement of its prohibitory provisions by the Treasury Department for many years. In March Igrg, however, the Supreme Court resolved the legal difficulty, ${ }^{6}$ and a campaign against pharmacists and physicians was commenced shortly thereafter. The first fruit of this activity in New York City was the arrest, on April 8, I9I9, of four pharmacists and six physicians. Within hours, hundreds of addicts, deprived of their regular source of supply, were besieging the Health Department for relief, in response to which a clinic was opened on April ro, r9ı. Following suit in similar situations, health departments in more than forty communities throughout the country started narcotic clinics of their own.

After the emergency situation was relieved, some of these clinics embarked on ambitious programs designed to cure physical addiction by a gradual diminution of the daily dose. Dr. Royal S. Copeland, Health Commissioner of New York City, foresaw the futility of this reduction procedure, however, and stated:7

In a sense, every citizen, especially the practitioner of medicine, is . . . committed to the hopelessness of the drug addict's fate. ...

The original intention in the establishment of this Clinic was to meet the urgent emergency of last April. It is now a clearing house, or admission bureau, preparing the way for the hospital treatment.... The Clinic has given us a hold on hundreds of addicts who, without it, would be lost to the municipal authorities. . . .

In I912, Dr. Charles E. Terry tried an experiment in Jacksonville, Florida, designed to lessen chronic use of opium derivatives. At the time, pharmacists were making counter sales to addicts without prescription. In consequence of a new law, however, permitting a city health officer to furnish prescriptions for narcotic drugs free of charge to those unable to pay for them, these counter sales ceased quickly and completely. But with the passage of the Harrison Act, the city clinic and the issuance of free prescriptions were promptly discontinued. The effect was sudden and dramatic: ${ }^{8}$

Immediately an illicit traffic sprang up, the price of the drug soared although the retail price in the drug stores remained the same, and ever since this period peddling has been as rife and as profitable in Jacksonville as elsewhere.

Years later, Dr. Terry, in commenting on this experience, observed: ${ }^{8}$

The only way that peddling will ever be controlled is through the intelligent application of our medical knowledge of the needs of the situation in such a manner as to make peddling unprofitable. By this I mean ... that narcotic drug addicts must be supplied

- United States v. Doremus, 249 U. S. 86 (Ig19).

7Copeland, The Narcotic Drthg Evil and the New York City Health Department, 26 AM. MEdicine 17, 18, 19 (1920).

${ }^{8}$ Charles E. Terry and Mildred Peliens, The Opiums Problem 849-50 (r928).

' Terry, Narcotic Drug Addiction and Rational Administration, 26 AM. Medrcise 29, 35 (1920). 
with the drug of their addiction until such time as successful and satisfactory treatment is available....

The Los Angeles clinic was opened on March 8, r920, and, by order of federal authorities, was closed on August 17 of the same year. Shortly thereafter, Dr. Buchler, who had been in charge of this clinic, stated:10

From the many letters received at the time of the clinic's last days we glean one salient fact, that with the clinic operating these unfortunates were able to work, and have the ideal of normal men to look up to. Some who came to the clinic ragged and filthy left it with decent clothes, a bank account, and a sense of having been a part of the machinery of production. Just what will become of those who prospered with the clinic is open to rather dismal conjecture.

Every day since the clinic has closed there have been patients, their relatives and friends, come to tell us of the tragedies that followed in the wake of these addicts' failure to get their morphia. Families have been broken up, men and women have lost their jobs, others have gone where the drug is accessible-all of this cemented together with suffering that takes courage to see.

The Shreveport clinic was opened on May 3, 1919, but was discontinued, along with the narcotic dispensaries in New Orleans and Alexandria, by the Louisiana State Board of Health, after consultation with federal officials, on March 15, r92I. On the following day, Dr. Butler, the director of the clinic, had it reopened through the authority of the City Council, but it was finally closed in February 1923-the last one in the country.

Since the closing of the dispensary, Dr. Butler reports the deaths of several former patients, three of these in jails in other cities, while a number of his patients have been sent to the state penitentiary. Of the remainder of the one hundred and one incurable cases, Dr. Butler continued to care for forty for about a year. The others he states were supplied by peddlers at $\$ \mathrm{I} .00$ or more a grain, inasmuch as their physicians refused to care for them. Individuals who during the life of the dispensary were leading decent lives and supporting their families reached a condition of wretched poverty.11

In 1920, a committee of the Shreveport Medical Society appointed to investigate the clinic reported $:^{12}$

It is significant that Dr. Butler's judicious and tactful conduct of the Clinic has secured for him the unqualified support and the cooperation of the Federal, State, Parish and City Authorities, and the State and City Boards of Health. In brief, we wish to express our unqualified support and approval of the Shreveport Narcotic Clinic and its systematic and effective administration by Dr. Butler.

Narcotic clinics, such as those described above, are said to have been failures, as they did not cure addiction. And in this respect and perhaps others, their shortcomings cannot be denied. Nevertheless, experience with them, short-lived though it was, demonstrated that many addicts, when furnished with their narcotic drug

${ }^{20}$ Terry \& PelleNs, op. cit. supra note 8 , at 875 .

${ }^{11}$ Id. at 870 .

12 Id. at 871 . 
requirements at a price they could afford to pay, resumed their places in society as useful, law-abiding, self-supporting citizens. Can as much be said for the system of narcotic drug control that has replaced these "failures"?

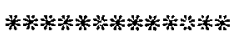

Against the dark record of our experience with narcotic drug addiction in the United States, the experience of many other western countries stands in graphic contrast. There, where physicians may dispense drugs to those in need of them, there is practically no narcotic drug black market, addicts are rarely involved in crime, and the almost infinitesimally small number of addicts has been steadily decreasing. ${ }^{13}$ Why we have not undertaken to adapt this simple and effective method -in such a manner, perhaps, as has been suggested by the New York Academy of Medicine-has been a source of amazement to most of those who have studied the problem.

One final thought should be emphasized. Under the proposals of the New York Academy of Medicine, narcotic drugs would be made available at low cost, under proper medical supervision, to carefully screened addicts whose needs, nonetheless, would still be most compelling. This plan would not necessarily cure addiction; but it would enlist the rigorous discipline of the drug on the side of law and order, rather than against it.

${ }^{10}$ For a more detailed discussion of the British philosophy and practice, see Lindesmith, The British System of Narcotics Control, infra 138-54. 